IMDS

107,8

\section{4}

\title{
Adoption of mobile technology in business: a fit-viability model
}

\author{
Ting-Peng Liang, Chen-Wei Huang and Yi-Hsuan Yeh
} Department of Information Management, National Sun Yat-sen University, Kaohsiung, Taiwan and

Binshan Lin

Department of Management and Marketing, Louisiana State University-Shreveport, Shreveport, Louisiana, USA

\begin{abstract}
Purpose - This paper aims to study the adoption of mobile technology in business and its determinants. A diagnostic tool for proper adoption of mobile technology is developed.

Design/methodology/approach - Grounded on the fit-viability framework, the paper uses a multi-case study via the fit and viability dimensions to examine the success or failure of mobile technology applications in business.

Findings - By drawing upon multiple streams of theory building, the paper is able to develop a set of measurement instruments to assess the fit and viability in adopting mobile technology. The findings demonstrate that the fit-viability model (FVM) provides useful guidelines for enterprises in their decisions on whether to adopt a mobile technology.

Research limitations/implications - First, the theoretical generalizability of the FVM needs to be more carefully observed in future studies. Second, the findings are exploratory and more extensive studies may be necessary.

Practical implications - Chief information officers and managers can use the developed instrument to measure the fitness and viability of implementing mobile technology in organizations. This should be able to increase the possibility of success.

Originality/value - This is one of the first papers to combine the fit and viability aspects and to empirically demonstrate the value of this two-dimensional model.
\end{abstract}

Keywords Mobile communication systems, Transaction costs

Paper type Research paper

\section{Introduction}

Mobile commerce is viewed as the next generation e-commerce. It refers to any transactions, either direct or indirect, via mobile devices, such as phones or personal digital assistants (PDAs). The most significant features of mobile technology are mobility and portability. The ability to access services ubiquitously, on the move, and through wireless networks and various devices. To date, mobile technologies have been applied to consumer-oriented areas, and most applications focus on voice communication rather than wireless data transformation. Large-scale usages are still scare in the business world (Gebauer and Shaw, 2004). Although there is a general notion in which mobile technologies could be applied in business, very little has been done in exploring how to enhance

Industrial Management \& Data Systems

Vol. 107 No. 8, 2007

pp. 1154-1169

(c) Emerald Group Publishing Limited 0263-5577

DOI $10.1108 / 02635570710822796$

This research was partially supported by grants from the National Science Council under contract No. 93-2416-H110-006 and from the Ministry of Education under the project of Universities Pursuing Research Excellence. 
business processes, what the implications of mobile technologies are, or what critical factors affect the success or failure of mobile technology applications.

Adopting mobile technology may create two kinds of impacts on business operations. The first is to facilitate communication among employee, customer and supplier. Through the enhancement of communicating efficiency and information timeliness, mobile technology can increase organizational productivity and profitability. The second is to re-vitalize business processes through changing data access patterns. For example, insurance agents are able to use mobile technology to provide timely services.

Quite a few studies on the application of mobile technology have been published (Matskin and Tveit, 2001; Lee and Ke, 2001; Kannan et al., 2001; Balasubramanian et al., 2002). Most of them focused on exploring the effect of short massage advertising (Tsang et al., 2004), investigating how to design a proper mobile device, how to enhance the accuracy of contents of short massage via information technology (IT), and how to add value into products and service (Raisinghani, 2001; Varshney, 2003; Tarasewich et al., 2002; Varshney and Vetter, 2002). Few have studied how a company decides on adopting mobile technology and what factors affect the success or failure of adopting mobile technology.

In an early work, Liang and Wei (2004) proposed a fit-viability model (FVM) that combines the theory of task/technology fit with the general notion of organizational viability of IT. In their research, a two-dimensional matrix that includes fit and viability as its frames was used to assess the likelihood of successful applications. This conceptual model provides a useful guide for further elaboration and evaluation of a general framework for successful technology adoption.

The purpose of this study is two-fold. First, we would like to extend the conceptual model and develop operable instruments for using the FVM. Second, we would like to evaluate the model and examine factors that may lead to successful adoption of mobile technologies.

In the remainder of this paper, extant literature is reviewed to identify factors that may affect the adoption of mobile technology in business. We then describe a multi-case study to examine the relationship between fit, viability and performance. Finally, research findings are reported. Our results show that the FVM can indeed help organization evaluate whether it is advantageous to adopt mobile technologies.

\section{Literature reviews \\ M-commerce}

Many different definitions of mobile commerce exist in the literature (Turel and Yuan, 2006), but these usually refer to e-commerce activities via mobile devices such as mobile phones and PDA. Mobility and reachability are two main characteristics of m-commerce (Liang, 2002). Compared with traditional e-commerce, transactions are generally conducted through personal computers (PCs) and laptops. M-commerce applications provide the potential with more freedom for organizations and users to perform various commerce-related tasks without the limitation of time and location (available anytime from anywhere). In addition, the economic value (Figure 1) contributed from $\mathrm{m}$-commerce is more than that from e-commerce, such as product and service localization, personalization, ubiquity enhancement, instant connectivity and convenience (Forrester Research, 2000; Siau et al., 2001).

Khalifa and Cheng (2002) investigated the role of exposure to mobile technology in the adoption of mobile commerce. Exposures such as trials of new devices, communication, 
IMDS

107,8

1156

Figure 1.

The characteristics and economic value of m-commerce and observation, etc. were found to have significant effect on a customer's decision to adopt mobile commerce. Wu and Wang (2005) presented an extended technology acceptance model to explore what determines user mobile commerce acceptance. DelVecchio and Seeman (2007) conducted discriminant analyses of filed sales force adoption of mobile technologies. These findings provide a basis for our study.

\section{Fit-viability model}

For measuring whether a technology is properly used, Tjan (2001) proposed the use of two dimensions in evaluation internet initiatives. One is fit and the other is viability. Fit measures the extent to which new network applications are consistent with the core competence, structure, value and culture of organization. Viability measures the extent to the value-added potential of new network applications, requirements of human resource, capital needs and so on. These two dimensions form a simple matrix with fit as the horizontal axis and viability as the vertical axis.

Adapting Tjan's strategic matrix to m-commerce applications, Liang and Wei (2004) provided a fit-viability framework that combines the theory of task/technology fit with the general notion of organizational impact of IT. In their framework, viability measures the extent to which the organizational environment is ready for the application, such as economic costs and benefits, users' readiness to use, and the maturity of organizational infrastructure to support mobile technology. Since, the key features of mobile technology are mobility and reachability, fit measures the extent to which the capabilities of mobile technology meet the requirement of task, such as location-sensitivity and time-critical needs of a particular service.

By the four categories in the matrix, a company could easily project the best strategy for the application of each mobile technology. Four alternatives are identified: good target, organizational restructuring, finding alternative technology, or forget it (Figure 2). For example, an application that rates high on viability but low on fit means the organization is ready but the task does not fit the nature of mobile technology. Hence, the best strategy is to find alternative technology that fits the nature of the task, instead of rushing onto the bandwagon of $\mathrm{m}$-commerce. While one that rates high on fit but low on viability would need to examine whether organizational restructuring could improve its economic prospects before actual implementation. Only those applications with good task-technology fit (TTF) and strong organizational viability are good targets.

Task-technology fit

The theoretical foundation for the fit dimension is the TTF perspective that argues a better fit between technological characteristics, task requirements, and individual

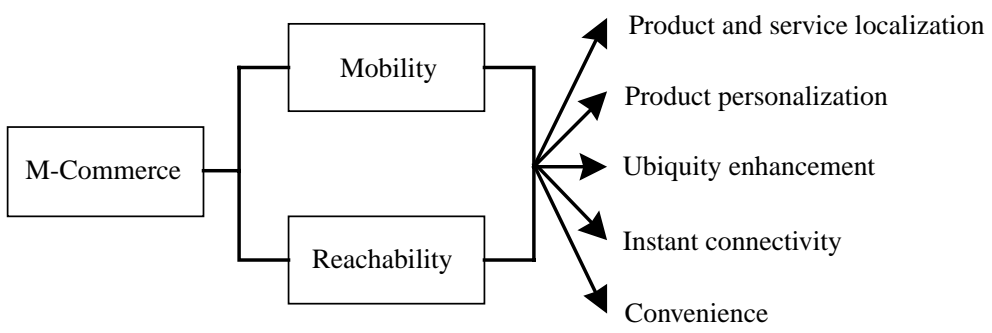

Source: Liang (2002) 
abilities will lead to better performance (Goodhue and Thompson, 1995). In the FVM, however, the construct is modified from the perceived fit in the TTF model to use more objective assessment of the match between task and technology with no consideration of individual abilities. That is, fit only considers the nature of technology and the requirements of task itself. Individual factors are considered to be part of the organizational viability. When the FVM is applied to mobile technology, mobility and reachability are considered two salient features for assessing the fit. Junglas and Watson (2003) proposed that mobile technology applies to task associated with time-, location- and identity-dependent features. If the requirements of task coincide with these attributes, its fit with mobile technology would be high. Therefore, the fit of the FVM is determined by questions such as: does the user need to access data in the database when on the move to different places? Is timeliness very important to task performance?

\section{Viability}

Viability refers to the extent to which the infrastructure of the organization is ready for the application. This needs to consider the general economic feasibility, technical infrastructure and the social readiness of the organization. In fact, many organizational factors have been identified to be critical to the success of IT implementation. Some of the prominent ones are described below.

The first aspect related to the readiness of an IT application is the economic feasibility, which includes two different aspects. One is to assess the cost benefit of the particular IT project to see whether the investment can bring in adequate financial or intangible returns; the other is to see whether IT can affect the transaction costs and hence lead to competitive advantages to the organization.

The cost-benefit of investment is obvious and many approaches such as assessing the net present value have been proposed in various textbooks. From the transaction cost aspect, reducing transaction cost can increase customer's willingness to use a technology. Factors affecting transaction cost include asset specificity, uncertainty and frequency (Williamson, 1975). Assets specificity covers five aspects, including human resource asset, location, physical asset, time and brand asset. Uncertainty will increase transaction costs due to high risks (Miller, 1992). A high-transaction frequency can reduce transaction costs and hence increasing the usage of specific asset.

With respect to organizational factors, existing literature has identified many potential factors, such as top management support and cognition (Umble et al., 2003; Ang et al., 2002), IS literacy of project team member (Umble et al., 2003; Poon and Wagner, 2001), user's personality and past experiences, etc. For example, Ang et al. (2002) used user

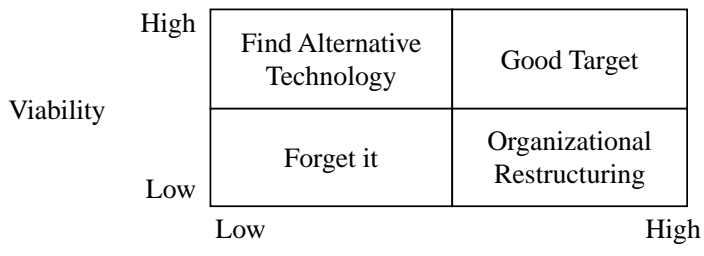

Fit
Figure 2. The fit-viability framework
Source: Liang and Wei (2004)

1157 
IMDS

107,8

1158

Figure 3.

Research framework satisfaction and system use to measure the success of IS implementation when studying an MRP system. Poon and Wagner (2001) also suggested that system usage, system usability and user satisfaction could be used to evaluate whether IS implementation was successful. Delone and Mclean (2003) pointed out that IS success could be measured by seven factors, including information quality, system quality, service quality, intension to use, user satisfaction and benefit. To sum up, user satisfaction and system usage are the two common criteria for evaluating the success of IS implementation.

Applegate et al. (1999) defined IT infrastructure as "a blueprint which combines the concept of physical space and Internet space." The blueprint includes two main parts, IT infrastructure and business opportunities. In IT infrastructure, it comprises IT platform and diverse information service required for supporting a particular application, such as information management, communication channels, the structure and control of the platform, and different functional application systems. Business opportunities consist of commerce, content and communities. In addition, Weill and Vitale (2002) pointed out that "IT infrastructure is composed of IT components, human IT infrastructure, shared IT services, and shared and standard applications."

Therefore, we can conclude that IT infrastructure of an organization has to include computing, information management and communication platforms. It provides the necessary foundation to support technological operation, and enhance business development.

\section{Research framework and methodology}

The research framework, as shown in Figure 3, illustrates the constructs described in the previous section. Fit is measured by matching the characteristics of task and technology. Viability is measured by the economic, IT infrastructure and organization readiness of the project.

Task characteristics related to mobile technology include timeliness and mobility. The timeliness of task characteristic means that performing the task needs timely information to support, and mobility means that the user has to do his job on the move in different place. Nature of the adopted mobile technology includes the portability of the mobile device and the ability of the mobile device to access and provide timely information.

For measuring the viability of an organization, asset specificity (need for special investment), uncertainty, and usage frequency are criteria for the economic aspect. IT infrastructure is measured by the software and hardware maturity, data management and the competency of the IS staff. Organizational factors include the

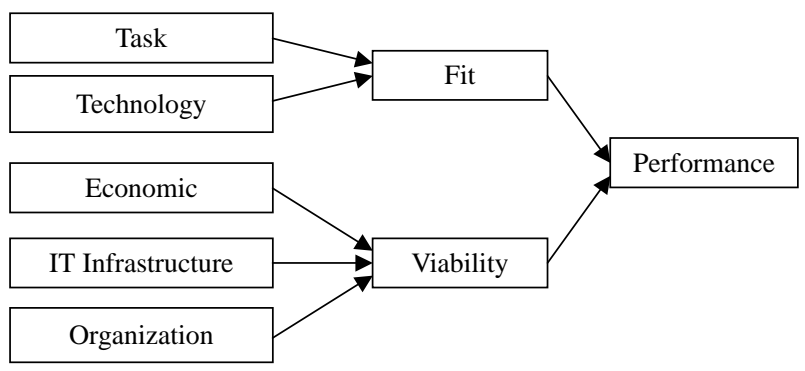


process reengineering, employee and top management support. We adopted Adair's research to divide the business process reengineering into four categories: maintenance-based (that reengineers about 10 percent of the original process scope), continual-based (that reengineers about 10 to 50 percent), thorough-based (that reengineers about 50 to 90 percent), and redesign-based (that redesigns process). The performance of adopting mobile technology is measured by system usage and user satisfaction.

All items for measuring fit and viability use the seven-point Likert-scale ( 1 = strongly disagree and $7=$ strongly agree). The Appendix shows a sample instrument.

Since, mobile technology is new and this research is exploratory in nature, we use the multi-case approach to demonstrate the use of the FVM. The research process includes the following steps:

- defining research framework and scope;

- designing research instruments, including questionnaires;

- identifying sample firms and key contact persons;

- data collection from interviews, web sites, and other available sources; and

- data analysis and conclusion.

After an extensive search, we selected four firms in different industries for further investigation. The firms selected include a convenience store chain, an air conditioner manufacturing, a medical logistics company and a life insurance service. Each of them has implemented mobile technology for more than one year. Firm $\mathrm{C}$ has three applications and Firm D has two applications, which made a total number of applications under study to seven. Table I shows their background information. The key informants in the study include chief information officers and leaders of the mobile commerce project. Four informants were interviewed in each case.

\section{Research findings}

The researchers interviewed key informants in the sample firms using the instrument developed in the previous section. The fit and viability in economic, IT infrastructure and organizational aspects were assessed. The resulting scores on different aspects from the study were shown in Table II. They are described below.

\begin{tabular}{|c|c|c|c|c|}
\hline Firm & $\mathrm{A}$ & B & $\mathrm{C}$ & $\mathrm{D}$ \\
\hline Industry & $\begin{array}{l}\text { Convenience } \\
\text { store chain }\end{array}$ & Manufacturing & Medical distributor & $\begin{array}{l}\text { Insurance } \\
\text { agent }\end{array}$ \\
\hline Founded & 1988 & 1987 & 1988 & 2000 \\
\hline $\begin{array}{l}\text { Total number of } \\
\text { employees } \\
\text { Canital (US\$) }\end{array}$ & 1,800 & 340 & 260 & 2,680 \\
\hline $\begin{array}{l}\text { (million) } \\
\text { Implementation }\end{array}$ & 13 & 40 & 3 & 200 \\
\hline $\begin{array}{l}\text { (months) } \\
\text { Mobile } \\
\text { applications } \\
\text { Mobile device }\end{array}$ & $\begin{array}{c}18 \\
\text { Inventory } \\
\text { management } \\
\text { PDA }\end{array}$ & $\begin{array}{l}42 \\
\text { Knowledge } \\
\text { management } \\
\text { PDA }\end{array}$ & $\begin{array}{c}30 \\
\text { Taking order, tracking, } \\
\text { and collection } \\
\text { PDA }\end{array}$ & $\begin{array}{l}18 \\
\text { Policy and } \\
\text { collection } \\
\text { PDA }\end{array}$ \\
\hline Mobile device & PDA & PDA & PDA & PDA \\
\hline
\end{tabular}




\section{IMDS 107,8}

\section{0}

Table II.

A summary of total scores of mobile technology

\begin{tabular}{|c|c|c|c|c|c|c|c|c|c|}
\hline \multicolumn{2}{|l|}{ Construct } & \multirow{2}{*}{$\begin{array}{l}\text { Item } \\
\text { Project budget }\end{array}$} & \multirow{2}{*}{$\frac{A}{6}$} & \multirow{2}{*}{$\frac{B}{2}$} & \multirow{2}{*}{$\frac{\mathrm{C} 1}{6}$} & \multirow{2}{*}{$\frac{\mathrm{C} 2}{6}$} & \multirow{2}{*}{$\frac{\mathrm{C} 3}{6}$} & \multirow{2}{*}{$\begin{array}{l}\mathrm{D} 1 \\
5\end{array}$} & \multirow{2}{*}{$\frac{\mathrm{D} 2}{6}$} \\
\hline Viability & Economic & & & & & & & & \\
\hline & & Transaction cost & 6 & 6 & 6 & 6 & 6 & 6 & 6 \\
\hline & Scores & & 6 & 4 & 6 & 6 & 6 & 5.5 & 6 \\
\hline & IT infrastructure & Software and hardware & 6 & 1 & 6 & 6 & 6 & 6 & \\
\hline & & Data management & 5 & 2 & 6 & 6 & 6 & 6 & \\
\hline & & Competence of IS staff & 6 & 1 & 6 & 6 & 6 & 3 & \\
\hline & Scores & & 5.67 & 1.33 & 6 & 6 & 6 & 5 & \\
\hline & Organization & Business process & & & & & & & \\
\hline & & reeng & 6 & 2 & 6 & 4 & 4 & 6 & \\
\hline & & User competence & 2 & 2 & 6 & 2 & 2 & 5 & \\
\hline & & support & 6 & 2 & 6 & 6 & 6 & 6 & \\
\hline & Scores & & 4.67 & 2 & 6 & 4 & 4 & 5.67 & \\
\hline Total s & & & 5.45 & 2.44 & 6 & 5.33 & 5.33 & 5.39 & \\
\hline Fit & Task-technology & & & & & & & & \\
\hline & fit & & 6 & 5 & 6 & 6 & 6 & 6 & \\
\hline Total score & & & 6 & 5 & 6 & 6 & 6 & 6 & \\
\hline
\end{tabular}

Notes: C1 - selling system; C2 - collection system; C3 - delivery tracing system; D1 - policy recommendation; D2 - collection system

Firm A. Firm A is a convenience store chain of more than 700 stores. It used PDA to support inventory tracking, called MobiPad. Since, inventory tracking needs to be done on the shelf and the traditional manual approach was very time-consuming and error-prone. The nature of mobility and reachability of mobile technology fits the need of the task very well. The system provided useful support to the store manager. Therefore, the fit was assessed to be high and scored 6 out of the seven-point scale.

Economically, the system freed manager's time to do more valuable activities. Employee deployment and physical asset in organization were more flexible. The amount of convenience store in Taiwan has reached saturation point; hence every store competes intensely with each other. Customer requirements change rapidly. Therefore, environmental uncertainties are high, which allows the mobile technology to reduce the transaction costs. The frequency of system usage is about once a day. The overall economic feasibility was assessed to be medium to high and a score of 6 was given.

For the IT infrastructure, the point-of-sales system and the ERP system were running smoothly. Hence, the hardware and software infrastructure was assessed to be high (scored 6). Data management was reasonable, although some high-level data were not regularly provided. It is given a score of 5 . The IS department had ten employees on board, which is reasonably high and they participated professional training very often. The IS department also had good relations with subcontractors. Their competency was assessed high ( 6 point). These give the IT infrastructure an overall score of 5.67.

For organizational support, the system primarily changed the way inventory data were collected, from hand-writing to PDA. Therefore, impact on business process was not significant and top management also supported well. They both scored high (6 each). However, most store managers were quite old. With high employee turn-over rate, the effort on training along was extremely high, although the company did have 
good training programs. Therefore, the user competence scored low (2 points) and the average score of organizational support is 4.67 .

For this case, the average score of organizational viability is 5.45 and the fit score is 6 , which are high on both dimensions. Its success is reasonable.

Firm B. The mobile system project was initiated by the maintenance department to support its engineers. The PDA-based system provides its maintenance engineers with maintenance manuals and customer profile information when they go to the customer site to maintain air conditioners.

Before the project, the engineer had to carry 20 different manuals with them when they went to the customer site. The system put all those manuals and guidelines into the PDA, which was very handy. The nature of the maintenance work was also highly location and moderately time sensitive. However, the processing speed of PDA was slow and the small screen was hard to read, it reduced the engineers' willingness to use the system. Therefore, a fit score of 5 was given.

With respect to the organizational viability, the project was totally supported by the maintenance department. The central management did not offer much support. The cost for developing and maintaining the system was high for the department. The system did reduce the transaction cost by making the service easier, but put quite some burden on the budget of the department. Therefore, the economic viability was a medium score of 4 .

The department did not have a strong IT group and two engineers assigned to handle the system were air conditioner engineers, not IS professional. All participated employees were inexperienced in IS implementation. So the IT infrastructure was not strongly supportive and the average score was 1.33 .

The organizational support was also low because the central management provided limited support and most users did not like the small screen of PDAs when they needed to check the manual. Prior to the system, different engineers had their own approaches in performing the maintenance work, which may vary from customer to customer. With the system, a standard operating process for all engineers was implemented. The change of business process caused certain resistance from the engineer. Therefore, the organizational viability of the system was low and the average score was 2.

Firm C. Firm $\mathrm{C}$ was a distributor of health care products whose major customers were hospitals and drug stores. It had implemented three mobile applications at the time of our study: taking orders, product tracking on delivery, and collecting payments from customers. All these tasks required mobility and timely service. Therefore, the fit scores were assessed to be 6 .

Before adopting the PDA-based mobile system, laptops were provided to sales representatives, but the delivery and collection systems were upgraded from the paper-based approach. PDAs were used to replace the heavy laptop computers. Salespersons, deliverymen and collectors needed to use the system on a daily basis. It represents high usage frequencies for the mobile systems and they did pay off economically. Therefore, the score of the economic feasibility is 6 .

The firm had implemented several information systems, including a large-scale ERP system. It had good internal control and high integration of software and hardware. In addition, the project leader had good communication skills and was experienced in IS development. The IS personnel was also very professional. Therefore, we gave each dimension a high score of 6 for the IT infrastructure. 
IMDS 107,8

1162
With respect to organizational support, we found that these three applications were slightly different in the impact on business process and user competence, although the top management support was the same. The order-taking system had a process the same as before, but the other two systems required certain re-engineering of the old process. It was also found that the user in delivery and collection departments were less experienced in using PDA to support their work. Collectors and deliverymen required much more training than salespersons, due to their direct upgrade from paper-based system to PDAs. Therefore, the order taking system had high scores of 6 on all dimensions, but the organizational support for the other two systems was 5.33.

Firm D. Firm D was an international insurance company with branches in 16 Asia Pacific countries. It uses PDAs to support its representatives in selling policies by generating customized products to clients and collecting customer data and payments. As insurance agents has to travel to meet with their customers and help make decisions on their insurance policies, the fit between task and mobile technology is high.

It already had a PC version of the mobile life-insurance advising system before the system was ported onto PDAs. Therefore, the cost was low for the company. However, the salespersons were asked to purchase the PDAs, which added some uncertainties that some of them might not want to buy and hindered the likelihood of obtaining benefits. Therefore, we gave a 5.5 score. For the mobile collection system, all funds for software and hardware were provided by the company and were in the annual budget. The competition in life insurance is very high and the adoption of mobile technology should be able to reduce the transaction costs due to the uncertainty in delay decisions. The usage frequencies were also very high for both systems. The economic viability is high.

The IS department of the company had a total of more than 20 persons, which is pretty large. Part of its maintenance was outsourced to subcontractors. The case company had good information control and highly integrated software and hardware. Data security and access control were high. The mobile system was well integrated with other information systems in the company. However, many developers involved in the mobile project had no prior experience in deploying such systems. Therefore, the IT infrastructure was ready and scored high in most dimensions, except the competence of the IS personnel.

Top managers had very high regard for the manager, although he was inexperienced in system implementation. IT was viewed by top managers as a strategy to advance the competitiveness of the organization. Therefore, the organizational support was high. The only dimension that received low score was the user's competence of the collection system. This was because the system was implemented two years after the policy advising system was deployed. The collection system did not have the lap-top based prior system and was upgraded from the paper-based system. The user of the collection system needed more training. The policy advising system scored 5.67 and the payment collection system scored 4.

\section{Results and discussion}

Figure 4 shows the relative position of these seven mobile applications. As we can see, most of them have high fit, but system B had a low viability. The implication of this is that most organizations were aware of the importance of fit in selecting mobile applications, but might not assess the viability properly. A high fit does not guarantee system success. 


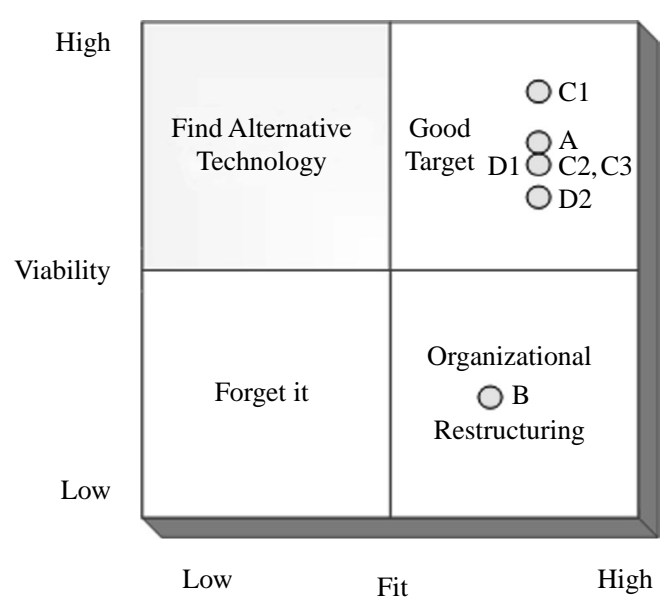

Figure 4.

For the mobile applications that we have investigated, six of them fall in the category of good target and one fall in organizational restructuring. This means, most applications had a good possibility of success and one would need organizational re-structuring before the implementation to ensure its success.

A major problem with the system in Firm B, located in the organizational restructuring category is lack of top management support. Without the support of the top management, the project was endangered. In addition to budget shortage, the user had low motivation to adapt the system. It also lacked assistance from the IS department. The system eventually failed. This confirms existing argument that top management support is crucial to system success.

The results from the case study show that the FVM is useful in evaluating the adoption of mobile technology. The data obtained from the case study also allow us to derive the following propositions for future study:

P1. The fitness between the nature of mobile technology and task characteristic is a critical factor for an organization to adopt mobile technology.

In our study, all seven cases have a high degree of fit. This implies that low-fit applications would have a low possibility of surviving management review in selecting new technology, although we cannot conclude that low-fit applications are impossible. Another issue with our findings is that we do not have a reliable instrument for measuring the degree of fit between task requirements and technology capabilities. If we can develop a more reliable instrument in the future, we may be able to assess the effect of different fit levels on system adoption:

P2. Organizational viability plays a key role in mobile system performance.

The only system that was unsuccessful was the B system that had low-organizational support. More specifically, it had poor IT infrastructure and low-organizational support. Systems A, C2, C3, D1, and D2 had low user competence but did not significantly affect their performance. This implies that user competence may be built through training and other means, but weaknesses in IT infrastructure and top management support may be devastating. Hence, we can further elaborate into the following two propositions: 
IMDS

107,8

\section{4}

P3. The maturity of IT infrastructure, as measured by the readiness software and hardware platform, data management, and competence of IS staff, is critical to a mobile system to perform.

P4. Organizational support, as measured by impact on business process, user competence, and top management support, has a significant impact on the performance of a mobile system.

\section{Conclusions}

The purpose of the paper is to present a framework for assessing the successful use of mobile technology in organizations. Based on the seminal work of Liang and Wei (2004) that extended the TTF model to become the FVM, we have successfully refined the FVM to become a useful tool.

In particular, we have defined the criteria for measuring fit and viability. Fit is measured by the match between task requirements and technology capabilities. Viability is measured by the economic feasibility, maturity of the IT infrastructure, and organizational support of an organization. They were further decomposed to include more detail items for measurement. The instrument provides useful guidelines for assessing the possible outcome of adopting a technology.

A multi-case analysis was then performed to explore the application of the FVM model in mobile technology applications. Seven applications in four companies were investigated through interviews and case analysis. The results show empirical support of such a model in assessing system use. Our findings lead to the development of four propositions.

The results of our study provide several theoretical and practical contributions. First and perhaps the most significant implication, is that managers need to take into account both TTF and organizational viability when considering the adoption of mobile technology. Most previous literature focused either on the fit aspect or organizational factors, which are incomplete by any means. Furthermore, we have successfully validated the fit-viability framework and show its applicability in practice. This should provide useful guidelines for practitioners.

Another implication of the research is that managers should take different strategies when they face system applications in different cell. For those in the good target category, they should go without hesitation. For those in the restructuring category, actions to strengthen organizational support are essential for their success. For those in the alternative technology and forget-it categories, a thorough and extensive evaluation before adoption is strongly suggested.

Despite its theoretical and practical contributions, this paper has some limitations. First, it is exploratory in nature and needs further studies for confirmation of the findings. Second, it is unclear to what extent the fit-viability framework can be generalized to other technology and issues. Its theoretical generalizability needs to be more carefully observed in future studies. Finally, we are not sure whether the nature of an industry or any other factors may play some roles in the model. Although, we have intended to include environmental and transactional uncertainty in our model as part of the transaction cost factors, but there may be more items that need to be examined when we evaluate the transaction cost and impact on process re-engineering. They will rely on future research to explore. 


\section{References}

Ang, J.S.K., Sum, C.C. and Yeo, L.N. (2002), "A multiple-case design methodology for studying MRP success and CSFs", Information \& Management, Vol. 39 No. 4, pp. 271-81.

Applegate, L.M., Mcfarlan, F.W. and Mckenney, J.L. (1999), Corporate Information Systems Management: Text and Cases, 5th ed., McGraw Hill, New York, NY.

Balasubramanian, S., Peterson, R.A. and Jarvenpaa, S.L. (2002), "Exploring the implications of m-commerce for markets and marketing", Journal of the Academy of Marketing Science, Vol. 30 No. 4, pp. 348-61.

DelVecchio, S. and Seeman, E. (2007), "Discriminant analyses of filed sales force adoption of wireless technologies", International Journal of Mobile Communications, Vol. 5 No. 1, pp. 32-47.

Delone, W.H. and Mclean, E.R. (2003), "The Delone and Mclean model of information systems success: a ten-year update", Journal of Management Information Systems, Vol. 19 No. 4, pp. 9-30.

Forrester Research (2000), "USD 7 trillion in e-commerce revenues by 2004", available at: www. nua.ie/surveys/index.c-gi?f $=$ VS\&art_id $=905355736 \&$ rel $=$ true

Gebauer, J. and Shaw, M.J. (2004), "Success factors and impacts of mobile business applications: results from a mobile e-procurement study", International Journal of Electronic Commerce, Vol. 8 No. 3, pp. 19-41.

Goodhue, D.L. and Thompson, R.L. (1995), "Task-technology fit and individual performance", MIS Quarterly, Vol. 19 No. 2, pp. 213-36.

Junglas, I.A. and Watson, R.T. (2003), "U-commerce: an experimental investigation of ubiquity and uniqueness", Proceedings of the International Conference on Information Systems, Seattle, December.

Kannan, P.K., Mei Chang, A-M. and Whinston, A.B. (2001), "Wireless commerce: marketing issues and possibilities", Proceedings of the 34th Hawaii International Conference on System Sciences, pp. 1-6.

Khalifa, M. and Cheng, S.K.N. (2002), "Adoption of mobile commerce: role of exposure", in Sprague, R.H. Jr (Ed.), Proceedings of the 35th Hawaii International Conference on System Sciences, IEEE Computer Society Press, Los Alamitos, CA.

Lee, C. and Ke, C.H. (2001), "A prediction-based query processing strategy in mobile commerce”, Journal of Database Management, Vol. 12 No. 3, pp. 14-26.

Liang, T.P. (2002), Decision Support Systems and Business Intelligence, Best Publishing Co., Taipei (in Chinese).

Liang, T.P. and Wei, C.P. (2004), "Introduction to the special issue: a framework for mobile commerce applications", International Journal of Electronic Commerce, Vol. 8 No. 3, pp. 7-17.

Matskin, M. and Tveit, A. (2001), "Mobile commerce agents in WAP-based services", Journal of Database Management, Vol. 12 No. 3, pp. 27-35.

Miller, K.D. (1992), "A framework for integrated risk management in international business", Journal of International Business Studies, Vol. 21 No. 2, pp. 311-31.

Poon, P. and Wagner, C. (2001), "Critical success factors revisited: success and failure cases of information systems for senior executives", Decision Support System, Vol. 30 No. 4, pp. 393-418.

Raisinghani, M.S. (2001), "WAP: transitional technology for m-commerce”, Information System Management, Vol. 18 No. 3, pp. 8-16. technology

in business 
IMDS 107,8

\section{6}

Siau, K., Lim, E.P. and Shen, Z. (2001), "Mobile commerce: promises, challenges, and research agenda", Journal of Database Management, Vol. 12 No. 3, pp. 4-13.

Tarasewich, P., Nickerson, R.C. and Warkentin, M. (2002), "Issues in mobile e-commerce", Communications of the Association for Information Systems, Vol. 8, pp. 41-64.

Tjan, A.K. (2001), "Finally, a way to put your internet portfolio in order", Harvard Business Review, Vol. 79 No. 2, pp. 76-85.

Tsang, M.L., Ho, S.C. and Liang, T.P. (2004), "Consumer attitudes toward mobile advertising: an empirical study", International Journal of Electronic Commerce, Vol. 8 No. 3, pp. 65-78.

Turel, O. and Yuan, Y. (2006), "Investigating the dynamics of the m-commerce value system: a comparative viewpoint", International Journal of Mobile Communications, Vol. 4 No. 5, pp. 532-57.

Umble, E.J., Haft, R.R. and Umble, M.M. (2003), "Enterprise resource planning: implementation procedures and critical success factors", European Journal of Operational Research, Vol. 146, pp. 241-57.

Varshney, U. (2003), "Wireless I: mobile and wireless information systems: application, networks, and research problems", Communication of the Association for Information Systems, Vol. 12, pp. 155-66.

Varshney, U. and Vetter, R.J. (2002), "Mobile commerce: framework, applications and networking support", Mobile Networks and Applications, Vol. 7 No. 3, pp. 185-98.

Weill, P. and Vitale, M. (2002), "What IT infrastructure capabilities are needed to implement e-business models?”, MIS Quarterly Executive, Vol. 1, pp. 17-34.

Williamson, O.E. (1975), Markets and Hierarchies: Analysis and Antitrust Implications, Collier Macmillan Publishers, New York, NY.

Wu, J.H. and Wang, S.C. (2005), "What drives mobile commerce? an empirical evaluation of the revised technology acceptance model”, Information \& Management, Vol. 42, pp. 719-29.

\section{Further reading}

Attaran, M. (2004), "Exploring the relationship between information technology and business process reengineering", Information \& Management, Vol. 41 No. 5, pp. 585-96.

Barnes, S.J. (2002), "The mobile commerce value chain: analysis and future developments", International Journal of Information Management, Vol. 22, pp. 91-108.

Eisenhardt, K.M. (1989), "Building theories from case study research", Academy of Management Review, Vol. 14, pp. 532-50.

Flanagin, A.J. (2000), "Social pressures on organizational website adoption", Human Communication Research, Vol. 26 No. 4, pp. 618-46.

Gressgard, L.J. and Stensaker, I. (2006), "The mobile service industry: strategic challenges and future business models", International Journal of Mobile Communications, Vol. 4 No. 5, pp. 509-31.

Grover, V., Goslar, M. and Segars, A. (1995), “Adopters of telecommunications initiatives: a profile of progressive US corporations”, International Journal of Information Management, Vol. 15 No. 1, pp. 33-46.

Koivumaki, T., Ristola, A. and Kesti, M. (2006), "Predicting consumer acceptance in mobile services: empirical evidence from an experimental end-user environment", International Journal of Mobile Communications, Vol. 4 No. 4, pp. 418-35. 
Liang, T.P. and Huang, J.S. (1998), "An empirical study on consumer acceptance of products in electronic markets: a transaction cost model”, Decision Support System, Vol. 24 No. 1, pp. 29-43.

Mahatanankoon, P., Wen, H.J. and Lim, B.B.L. (2006), "Evaluating the technological characteristics and trust affecting mobile device usage", International Journal of Mobile Communications, Vol. 4 No. 6, pp. 662-81.

Mehrtens, J., Cragg, P.B. and Mills, A.M. (2001), "A model of internet adoption by SMEs", Information \& Management, Vol. 39 No. 2, pp. 165-76.

Petroni, A. and Rizzi, A. (2001), "Antecedents of MRP adoption in small and medium-sized firms, benchmarking”, Benchmarking: An International Journal, Vol. 8 No. 2, pp. 144-56.

Rogers, E.M. (1995), Diffusion of Innovations, The Free Press, New York, NY.

Smith, A.D. (2006), "Exploring m-commerce in terms of viability, growth and challenges", International Journal of Mobile Communications, Vol. 4 No. 6, pp. 682-703.

Srinivasan, R., Lilien, G.L. and Rangaswamy, A. (2002), “Technological opportunism and radical technology adoption: an application to e-business", Journal of Marketing, Vol. 66 No. 4, pp. 47-60.

\section{Appendix. Research instrument}

1. Fits

Task requirements:

- Do users need to work on the move or in different place regularly?

- Will information delay significantly affect the performance of the task?

- Will the performance of the task be substantially poorer if it was performed in different place or at different time?

Technology characteristics:

- Does the technology allow the user to work at any place?

- Does the technology allow the user to work immediately when necessary?

\section{Viability}

(1) Economic. Project budget:

- Does the organization provide adequate budget for developing the system?

- Does the organization provide adequate budget for maintaining the system?

Asset specificity:

(1) Physical asset specificity:

- Does the adoption of mobile technology need to obtain special hardware/software?

- Does the use of mobile technology reduce the need for physical asset on-hand?

(2) Human asset specificity:

- Can users use mobile technology to better perform with no need of more training?

- Does the adoption of mobile technology need to hire employees with special expertise? 
IMDS

107,8

\section{8}

(3) Brand specificity:

- Does the adoption of mobile technology affect the value of the brand and partnerships?

Uncertainty:

- Whether the environment and business process are subject to frequent changes?

Frequency:

- Is the task supported by the mobile technology a frequent activity of the organization?

- Does the task need to use the mobile technology for information or decision frequently?

(2) IT infrastructure. Software and hardware:

- Does the organization have adequate hardware for operating the system?

- Does the organization are mature in using the Internet and related technology?

- Does the organization have qualified network management system?

- Does the organization have integrated databases or data warehouse?

- Does the organization have necessary software for implementing mobile applications?

Data management:

- Does the organization have established policies on data management and security?

The competence of IS staff:

- Does the project leader have prior experience in mobile applications?

- Is the IS personnel experienced in system development and maintenance?

- Does IS department know the business process well enough to implement the application?

- Are there any programs for alleviating user resistance?

- Does the organization have good outsourcing partners for IS projects?

(3) Organizational support. Process reengineering:

- Is the scope of process re-engineering due to technology adoption large?

User competence:

- Does the user have adequate knowledge of IT and mobile technology?

- Does the user have a high intention of accepting new technology?

- Does the user have high efficacy in using new technology?

Top management support:

- Do key executives in the corporate headquarter participate in the project decision?

- Do key executives in the corporate headquarter assigned members into the project team?

- Do key executives in the corporate headquarter appropriate adequate budget to finance the project? 
- Do key executives in the corporate headquarter use the system and/or encourage employees to use the system?

\section{Performance}

- Is the system usage consistent with the expectation?

- Does the user have a positive attitude toward the system?

- Does the system satisfy the user needs?

\section{Mobile technology in business}

1169

\section{Corresponding author}

Ting-Peng Liang can be contacted at: liang@mis.nsysu.edu.tw 